\title{
BAYES THEOREM AND THE PROBABILISTIC PREDICTION OF INTER-ARRIVAL TIMES FOR STRONG EARTHQUAKES FELT IN MEXICO CITY
}

\author{
Sergio G. FerRaes \\ Institute of Geophysics (UNAM), Ciudad Universitaria, Mexico City, Mexico \\ (Received May 4, 1985; Revised February 13, 1986)
}

The probabilistic estimation or prediction of future inter-arrival times $(T)$ of strong earthquake magnitudes ( $M \geq 6.5$, Richter scale), felt in Mexico City from 1908 to 1979 , is considered in terms of Bayes theorem. $P\left(T_{\mathrm{r}} / M\right)=$ $\left\{P\left(T_{\mathrm{r}}\right) P\left(M / T_{\mathrm{r}}\right)\right\} / \sum_{j=1}^{n} P\left(T_{j}\right) P\left(M / T_{j}\right)$. We require the posterior probability $P\left(T_{\mathrm{r}} / M\right)$, i.e., the conditional probability of the event $T_{\mathrm{r}}$, given that $M$ has occurred. $T_{0}$ determine the prior probability $P\left(T_{j}\right)$ and the likelihood function $P\left(M / T_{j}\right)$, we use two fundamental assumptions: (i) Random occurrence with the associated equal prior probabilities, (ii) Binomial likelihood function. However, the discrete Bayesian analysis of our earthquake sample is evaluated on the basis of the proportion of successes $(\pi)$, rather than in the number of successes. Thus, the Bayesian posterior distribution is the distribution of $(\pi)$ conditional on observing the sample with $X$ successes. The posterior distribution can be written in the form $P\left(\pi_{r s} / X\right)=\left(\begin{array}{c}n_{\mathrm{r}} \\ X\end{array}\right) \pi_{r s}^{X}\left(1-\pi_{r s}\right)^{n_{\mathrm{r}}-x} / \sum_{j=1}^{\beta}\left(\begin{array}{c}n_{\mathrm{r}} \\ X\end{array}\right) \pi_{r j}$ $\times\left(1-\pi_{\mathrm{r} j}\right)^{n_{\mathrm{r}}-X}$, where $\mathrm{r}$ stands for the specific midpoint earthquake magnitude class, $s$ stand for the specific time-interval class. The discrete Bayesian analysis of strong earthquakes felt in Mexico City, suggests that the probabilistic estimation or prediction of strong earthquakes (magnitudes) felt in Mexico City as follows:

Observed

(Occurrence time)

October 25, $1981\left(M_{\mathrm{s}}=7.3\right)$

June 7, $1982\left(M_{\mathrm{s}}=7.0\right)$

September, $1985(M=7.8)$
Predicted

(Occurrence time)

June, $1980(\bar{M}=7.3)$

January, $1982(\vec{M}=7.3)$

April, $1986(\bar{M}=7.8)$

It should be noted that very strong agreement exists between the Observed occurrence time and the Predicted occurrence time.

\section{Introduction}

The belts where destructive earthquakes have occurred have been mapped, GUTENBERG and RICHTER (1954), so we know approximately the geographical places where future earthquakes will occur; for example, the analysis of ALLEN 
et al. (1965), shows that earthquakes in Southern California release a strain consistent with the location of the major faults. However, we have not quite arrived at the capability of forecasting the specific time and magnitude of destructive earthquakes. Therefore, much attention is now being given to this problem because the economic cost of the strongest earthquake effects in terms of both death and property damage can hardly be envisaged.

The problem of the interrelation between earthquakes on the basis of the distribution of shocks in time has been investigated by several eminent earthquake scientists such as OMORI (1894), JeFFreYs (1938), CONRAD (1932), AKI (1965), Knopoff (1964) and others. Recently, Powell and DudA (1975) examined the dependence of earthquakes on the basis of the relative occurrence times and pointed out that the test revealed occurrence patterns for earthquakes which might otherwise appear to take place independently of each other. LoMmITZ (1966) gives a concise summary of the studies of the statistical dependence between earthquakes.

OGAWARA (1965), examined the prediction of the time interval before the next felt earthquake occurs in Tokyo. Ogawara pointed out that a conditional prediction is derived under the condition that there was no earthquake from the last one up to the present.

ProCHÁzKOVÁ (1973) has pointed out that from the point of view of a longterm prediction, it is necessary to determine the time when strong earthquakes may be expected in a certain area of the region under investigation. Procházková (1973) discussed this problem when studying the determination of space and time tendency in the occurrence of earthquakes.

FERRAes (1975), has reported statistical inter-relation between the timeinterval $(T)$ of the consecutive earthquake and the associated magnitude $(M)$ of the preceding earthquake, for a sequence of earthquakes with a magnitude 4.5 or greater from an active seismic area of limited extent around Mexico City. Further, he pointed out that there is no statistical evidence showing that the following earthquake magnitude size depends upon the preceding elapsed time-interval.

Recently, similar earthquake behavior has been found by BuFE et al. (1977) for small earthquakes on the Calaveras fault in California.

More recently, SHIMAZAKI and NAKATA (1980), found regularity in large earthquake recurrence at three different sites of plate convergence around the Japan arcs. Finally, they pointed out that the time-interval between two successive large earthquakes is approximately proportional to the amount of coseismic displacement of the preceding earthquake and not of the following earthquake.

From the preceding paragraphs it is suggested that a common observed feature of association or dependence exists between the preceding earthquake magnitude (or the coseismic displacement) and the associated consecutive timeinterval. Therefore, it seems reasonable to investigate the probabilistic prediction of the length of inter-arrival time $(T)$ associated with the occurrence of certain preceding strong earthquake magnitudes $(M)$. In this way the Bayes' theorem is proposed as a method of using relevant information available about a set of 
successive strong earthquakes occurring in an active region around Mexico City, in order to get the probabilistic prediction of its occurrence inter-arrival time.

There are still so many unanswered questions concerning the problem of assigning prior probabilities $P\left(T_{j}\right)$ and the associated likelihood function $P\left(M / T_{j}\right)$, that we call this a preliminary study; but the simplified form of the Bayes theorem for such study has been developed with some definite results arrived at, which we believe are important enough to report on.

\section{Basic Bayesian Formulation of the Problem}

It seems reasonable that one should be able to use probabilities to measure the degree to which one is uncertain about what the true value is of the inter-arrival time $(T)$ of the next expected strong earthquake of magnitude $(M)$.

The prior-posterior Bayesian analysis is a possible strategy for the analysis of a set of data. It takes into account our knowledge of the unknown state of the world prior to collection of new data, and it permits an updating of our knowledge with the information in the new data. The updated knowledge reflects what we know prior to the new data.

Now, following BARBER (1973, p. 163), if the outcome is $M$, the probability that the event $T_{\mathrm{r}}$ has occurred is given by the discrete form of Bayes' theorem as follows

$$
P\left(T_{\mathrm{r}} / M\right)=\frac{P\left(T_{\mathrm{r}}\right) P\left(M / T_{\mathrm{r}}\right)}{\sum_{j=1}^{n} P\left(T_{j}\right) P\left(M / T_{j}\right)} .
$$

The above formula (1) gives us the probability of a particular $T_{r}$, given that event $M$ has occurred. The probabilities appearing in formula (1) have the following special designation: $P\left(T_{j}\right)$ is called the prior probability of the hypothesis $T_{j}$ (the probability before the new experiment), $P\left(M / T_{j}\right)$ is called the new data probability given $T_{j}$ or likelihood function, and $P\left(T_{j} / M\right)$ is called the posterior probability.

There is no disagreement with Bayes' formula. The disagreement arises from the usage of the theorem.

We may arrive at a prior distribution of $T_{j}$ after a certain amount of introspection. For instance, if we suppose that the earthquake magnitude $(M)$ and the length of the inter-arrival time $(T)$ occurs at random, it may be assumed equal to prior probabilities. In such case, the prior probabilities $P\left(T_{j}\right)$ and $P\left(T_{r}\right)$ are equal so that the Bayes' theorem, Eq. (1), simplifies to

$$
P\left(T_{\mathrm{r}} / M\right)=\frac{P\left(M / T_{\mathrm{r}}\right)}{\sum_{j=1}^{n} P\left(M / T_{j}\right)} .
$$

Now, in addition to the hypothesis of events whose occurrence is equally probable, we shall now assume that the process can be thought of as a Bernoulli 
process, with the assumptions of stationarity and independence appearing reasonable. That is, the probability that any one earthquake $\left(M_{i}\right)$ is follow by a consecutive inter-arrival time $\left(T_{j}\right)$ remains constant for all the earthquakes that have occurred and is independent of the past history of other earthquakes from the process. Under the assumptions that we have made, the sampling distribution of the number $X_{i j}$ of earthquakes $\left(M_{i}\right)$ having consecutive inter-arrival time $\left(T_{j}\right)$ in a sample $n$, given a particular value $\pi_{i j}$, is a Binomial distribution.

Following BARBER (1973, p. 144), the Binomial distribution gives the total probability of " $X$ " successes in " $n$ " trials by the formula

$$
P(X)=\left(\begin{array}{l}
n \\
X
\end{array}\right) \pi^{x}(1-\pi)^{n-x} . \quad(X=0,1,2, \ldots, n)
$$

Assuming that the random variable " $X$ " has a Binomial distribution with parameter $\pi$, for this study, may be a realistic assumption because our sample of magnitudes $\left(M_{i}\right)$ of the strong earthquakes may be taken from a very large amount of strong earthquakes which occurred during the past in the Mexico City seismic area.

To specify the parameter $\pi$, of the Binomial distribution, we follow LARSON (1974, example 9.2.3). According to Larson it is possible to show that the Bayesian estimate for the parameter $\pi$ of the Binomial distribution is

$$
\pi=\frac{X+1}{n+2}
$$

It should be noted that this Bayesian estimator increases the population size $(n)$ in 2 , and the number of successes $(X)$ in 1 , and produces the same proportion as that for the maximum likelihood estimator for the parameter $\pi$. More precisely, following TAYLOR (1974, p. 222) we can show that the maximum likelihood estimator for the parameter $\pi$, is the proportion of successes in the sample, then $\pi$ can be written in the form

$$
\pi=\frac{X}{n}
$$

Therefore, sufficient accuracy may be obtained by using the maximum likelihood estimator for $\pi$.

Now, if our data consists of a random set $\left\{M_{i}\right\}$ of magnitudes of strong earthquakes of sample size " $n$ ", " $X$ " of which are found to have a consecutive timeinterval $\left(T_{j}\right)$; then, the parameter $\pi_{i j}$ is of interest in the proportion of earthquake magnitudes $\left(M_{i}\right)$ possessing a consecutive time-interval $\left(T_{j}\right)$, and the relevant statistical distribution is the observed sample distribution of the proportion. More specifically, we are concerned about the proportion $\left(\pi_{i j}\right)$ of these earthquakes' magnitudes that are followed by the inter-arrival time $\left(T_{j}\right)$.

Now, following Parsons (1974, p. 435), if each sample is evaluated on the basis of the proportion of successes rather than the number of successes the pro- 
bability of observing $X$ successes is equivalent to observing a proportion of successes $(X / n)$ in a sample of size " $n$ ". Further, following Parsons (1974), and the theory above, the appropriate sampling distribution of $\pi_{i j}$ is obtained by simply dividing each of the observed values $X_{i j}$ by the sample size $n$. More precisely, by using Eq. (5).

Next, for a given value of $\pi_{i j}$, the likelihood function $P\left(M / T_{j}\right)$, is determined by the Binomial distribution, Eq. (3), and can be written

$$
P\left(X_{i j} / \pi_{i j}\right)=\left(\begin{array}{c}
n \\
X_{i j}
\end{array}\right) \pi_{i j}^{X_{i j}}\left(1-\pi_{i j}\right)^{n-X_{i j}}
$$

Finally, the posterior Bayesian distribution is the distribution of $\pi_{i j}$ conditional on observing the $X_{i j}$ successes in the sample $n$. In this case, the simplified form of the Bayes' theorem, Eq. (2), can be written in the form

$$
P\left(\pi_{\mathrm{rs}} / X\right)=\frac{\left(\begin{array}{c}
n_{\mathrm{r}} \\
X
\end{array}\right) \pi_{\mathrm{rs}}^{X}\left(1-\pi_{\mathrm{rs}}\right)^{n_{\mathrm{r}}-X}}{\sum_{j=1}^{\beta}\left(\begin{array}{c}
n_{\mathrm{r}} \\
X
\end{array}\right) \pi_{\mathrm{r} j}\left(1-\pi_{r j}\right)^{n_{\mathrm{r}}-X}},
$$

where $X$ represent the sample result. Here, the role of the inter-arrival time $\left(T_{\mathrm{x}}\right)$ in Eq. (2) is played by $\pi_{\mathrm{r}}$.

\section{Tectonic Location of the Strong Earthquake Data}

In tectonic terms western Mexico is a realm of earthquakes: it is a part of the Ring of Fire, the belt of earthquakes and volcanic activity that circles the Pacific Ocean. An active seismic belt follows the Pacific margin of western Mexico and Central America, paralleling the Middle American Trench.

In the theory of plate tectonics most major earthquakes arc explained as sudden movements of ruptures along the fault constituting the boundaries of the earth's great crustal plates. The Middle America seismic zone extends along western Mexico and Central America between $82.5^{\circ} \mathrm{W}$ and $105^{\circ} \mathrm{W}$, defining the northeastern boundary of the Cocos plate. Both the tectonic and volcanic pattern of the region of Mexico is substantially influenced by the subduction (thrusting) of the Cocos plate beneath the North American and Caribbean plate (MOLNAR and SyKes, 1969; DeAN and DraKe, 1978) with about a N $30^{\circ} \mathrm{E}$ direction of convergence (CARR, 1974).

Further, it appears that the main factors governing the processes of subduction and determining the morphology of the Wadati-Benioff zone in this region, are the proximity of the East Pacific Rise with the Middle America Trench and the complicated bathymetry of the Cocos plate (HANUS and VANEK, 1977-1978).

From a causal analysis of the epicenters of a set of strong earthquakes felt in Mexico City, it was found that they apparently have epicenters concentrated in a narrow seismic region around Mexico City, which extends from longitudes 
$96^{\circ} \mathrm{W}$ to $105^{\circ} \mathrm{W}$ and from latitudes $16^{\circ} \mathrm{N}$ to $19^{\circ} \mathrm{N}$ (Ferraes, 1973). At this point, SingH et al. (1983), studied the seismo-tectonic of four regions along the Mexican subduction zones. The regions have been named Oaxaca, Guerrero, Michoacan and Jalisco. They noted that the seismicity of the Jalisco region is related to the subduction of the Rivera plate below the North American plate, whereas in the other three regions it is related to the subduction of the Cocos plate. According to SingH et al. (1983), the four regions extend from latitudes $15^{\circ} \mathrm{N}$ to $20.1^{\circ} \mathrm{N}$ and longitudes $95^{\circ} \mathrm{W}$ to $105.5^{\circ} \mathrm{W}$. It should be noted that the epicenter of the strong earthquakes felt in Mexico City are located in the tectonic region studied by SrNGH et al. (1983). Therefore, all their tectonic conclusions are applied to the set of earthquakes analyzed in this study.

\section{Strong Earthquakes for Mexico City Area}

The earthquake data analyzed here covers a time period of 71 years starting from 1909 to 1979 and has been taken from the earthquake catalog prepared by ABE (1981), and from bulletins of the Coast and Geodetic Survey (U. S. C. and G. S.). These large magnitude earthquakes have epicenters apparently concentrated in a narrow seismic region around Mexico City, which extends from longitudes $96^{\circ} \mathrm{W}$ to $105^{\circ} \mathrm{W}$ and latitudes from $16^{\circ} \mathrm{N}$ to $19^{\circ} \mathrm{N}$. Thus we have a series of large earthquakes occurring over a small area or in a small volume of the earth.

To avoid biased statistics because of the presence of aftershocks and foreshocks in the catalog, large earthquakes appear as discrete events, and we have selected our strong earthquake magnitudes sample using the procedure outlined by FERRAES (1985), to remove aftershocks and foreshocks from the original data. However, no matter what the method for the removal of aftershocks and foreshocks events is, we can never be sure that our earthquake samples are genuinely representative of a sequence of main shocks. For example, RUNDLE and JACKSON (1977) described a procedure to generate synthetic earthquakes and they stated: we did find that some events had the appearance of being aftershocks by virtue of their proximity in space and time to other events. Removal of these events from the catalog by an algorithm similar to that used by GARDNER and KNOPOFF (1974), generally improved the Poissonicity. Thus, there is a hint of circularity in the arguments of Gardner and Knopoff, in that their definitions of "aftershocks" is applicable to most of the non-Poissonian events, be they aftershocks or mainsequence events.

In this study, in order to describe the sample space of our earthquake experiment; we were first concerned with selecting strong earthquakes $(M \geq 6.5$, Richter scale) felt in Mexico City and recording their occurrence time and magnitude. Second, we wanted to assign a successive (consecutive) inter-arrival time $\left(T_{j}\right)$ to every magnitude $\left(M_{i}\right)$ of a strong earthquake of our sample space. With this in mind, we selected the following list of strong earthquakes given in Table 1. 
Table 1. Occurrence time (year) and magnitude (Richter scale) for the sample of strong earthquakes felt in Mexico City from 1909 to 1979.

\begin{tabular}{cccccc}
\hline $\begin{array}{c}\text { Occurrence } \\
\text { time } \\
\text { (year) }\end{array}$ & $\begin{array}{c}\text { Magnitude } \\
\text { (Richter) }\end{array}$ & $\begin{array}{c}\text { Occurrence } \\
\text { time } \\
\text { (year) }\end{array}$ & $\begin{array}{c}\text { Magnitude } \\
\text { (Richter) }\end{array}$ & $\begin{array}{c}\text { Occurrence } \\
\text { time } \\
\text { (year) }\end{array}$ & $\begin{array}{c}\text { Magnitude } \\
\text { (Richter) }\end{array}$ \\
\hline 1909.57540 & 7.75 & 1933.94530 & 6.50 & 1957.56992 & 7.50 \\
1910.72336 & 6.90 & 1934.07672 & 6.70 & 1958.33428 & 6.50 \\
1911.09042 & 7.25 & 1934.82200 & 7.00 & 1959.39456 & 6.80 \\
1911.43018 & 7.90 & 1935.49320 & 6.90 & 1962.35894 & 7.10 \\
1911.64938 & 6.70 & 1937.56444 & 7.70 & 1964.50964 & 6.30 \\
1911.95352 & 7.00 & 1937.75350 & 7.20 & 1965.63842 & 6.90 \\
1912.87406 & 7.80 & 1937.97818 & 6.50 & 1968.58088 & 7.00 \\
1920.00822 & 7.80 & 1938.00548 & 7.25 & 1972.16614 & 7.50 \\
1928.00274 & 6.25 & 1938.33428 & 6.50 & 1973.08220 & 7.30 \\
1928.10960 & 7.70 & 1941.29109 & 7.00 & 1973.65212 & 6.80 \\
1928.22468 & 7.50 & 1942.90180 & 7.25 & 1975.30962 & 6.50 \\
1928.29318 & 7.75 & 1943.14248 & 7.50 & 1978.21646 & 6.60 \\
1928.45758 & 7.90 & 1945.76994 & 6.50 & 1978.90146 & 6.50 \\
1928.58636 & 7.30 & 1946.43018 & 7.10 & 1979.20276 & 7.00 \\
1928.76446 & 7.40 & 1946.52334 & 6.50 & & \\
1931.03836 & 7.50 & 1950.94804 & 7.30 & & \\
1931.82748 & 6.70 & 1951.98640 & 6.50 & & \\
1932.41922 & 8.10 & 1956.01192 & 6.40 & & \\
1933.35072 & 6.70 & 1957.27400 & 6.75 & & \\
\hline
\end{tabular}

Next, to obtain the frequency distribution of observed strong earthquake magnitude classes versus the time-interval classes, the sequence of 52 successive strong earthquakes magnitudes were arranged in order of increasing $M$ (Richter scale) and grouped into a number of convenient sized classes with intervals of magnitude $\Delta M=0.4$, so that each individual strong earthquake is placed into a particular class and the results take the form of frequencies with which the individual earthquakes fall into these. At this point FURUMOTO (1966) has pointed out that the scatter is reduced using the intervals of magnitude $\Delta M=0.5$ and for purposes of prediction there is no loss of information by using this magnitude interval.

Finally, the time that elapses between successive strong earthquake occurrences (say $M_{1}$ and $M_{2}$ ) being one after another, is referred to as the inter-arrival time amplitudes. The sequence of successive inter-arrival time amplitudes, say $T_{j}=t_{2}-t_{1}$ (in years), are measured and grouped into a number of convenient sized classes. The shortest length of inter-arrival time was found to be 10 days and the largest one about 8 years. Table 2 gives the observed frequencies $X_{i j}$ of our earthquake population, every member of which bears one of the values of the classes of magnitude intervals $\Delta M_{i}$ versus the classes of the inter-arrival times $\Delta T_{j}$. Thus the Mexico City strong earthquakes $(M \geq 6.5)$ are grouped according to the classintervals of the two variables, time-interval and magnitude, therefore, we have an observed bivariate frequency-distribution. 
Table 2. Contingency table of observed frequencies $X_{i j}$. The rows classify the preceding earthquakes in magnitude class $\Delta M_{i}$ while the columns classify the consecutive inter-arrival times according classes $J T_{j}$. The bivariate distribution correspond to the catalog given in Table 1 for Mexico City earthquakes $(M \geq 6.5)$.

\begin{tabular}{lrcccccccc}
\hline & \multicolumn{10}{c}{$\Delta T_{j}^{*}$} \\
\cline { 2 - 9 } & 180 & 360 & 540 & 720 & 900 & 1,080 & 1,260 & 1,440 \\
& 0 & 180 & 360 & 540 & 720 & 900 & 1,080 & 1,260 \\
\hline $6.5-7.0$ & 7 & 7 & 3 & 2 & 1 & 3 & 1 & 1 \\
$7.1-7.5$ & 7 & 4 & 1 & 0 & 2 & 1 & 0 & 0 \\
$7.6-8.0$ & 5 & 1 & 1 & 0 & 0 & 0 & 0 & 0 \\
Total & 19 & 12 & 5 & 2 & 3 & 4 & 1 & 1 \\
\hline
\end{tabular}

\begin{tabular}{lcccccccc}
\hline & \multicolumn{10}{c}{$\Delta T_{j}{ }^{*}$} \\
\cline { 2 - 8 } & 1,620 & 1,800 & 1,980 & 2,160 & 2,340 & 2,520 & 2,700 & Total \\
& 1,440 & 1,620 & 1,800 & 1,980 & 2,160 & 2,340 & 2,520 & \\
\hline $6.5-7.0$ & 2 & 0 & 0 & 0 & 0 & 0 & 0 & 27 \\
$7.1-7.5$ & 0 & 0 & 0 & 0 & 0 & 0 & 0 & 15 \\
$7.6-8.0$ & 0 & 0 & 0 & 0 & 0 & 0 & 2 & 9 \\
Total & 2 & 0 & 0 & 0 & 0 & 0 & 2 & 51 \\
\hline
\end{tabular}
scale).

* $\Delta T_{j}$, inter-arrival time class (in days); $\Delta M_{i}$, earthquake magnitude class (Richter

Now, in order to use Eq. (7) to estimate the Bayesian posterior probabilities we have to determine the values of the Binomial likelihood function, Eq. (6). To do this we need the observed distribution of the parameter $\pi_{i j}$, i.e., the proportion of successes.

Our earthquake prediction procedure is an attempt to relate the earthquake occurrence time $(t)$ to the trend changes in observed inter-arrival times $\left(T_{j}\right)$. Therefore, we want to study the variations (or suspected variations) in the occurrence of individual inter-arrival times classes $\left(\Delta T_{j}\right)$ associated with the preceding strong earthquake magnitude classes $\left(\Delta M_{i}\right)$. Then, we give equal weight to all the earthquakes in each possible earthquake magnitude class interval by assigning a number or weight, the midpoint magnitude $\bar{M}_{i}$. Similarly, we give equal weight to all of the associated consecutive inter-arrival times in each possible class interval by assigning the midpoint inter-arrival time $\bar{T}_{j}$.

Finally, to develop a posterior discrete distribution of time-intervals occurrences that account for the uncertainty in earthquake magnitude, the set $\left\{T_{j}\right\}$ of inter-arrival times are grouped into three convenient sub-sets having a preceding midpoint earthquake magnitude class $\bar{M}_{1}, \bar{M}_{2}$, and $\bar{M}_{3}$. Then, we will have three sub-samples (one for each midpoint magnitude), each one with size $n_{1}, n_{2}$, and $n_{3}$. It should be noted that in Table 2, the three sub-sets of inter-arrival times with preceding earthquake magnitude classes $\Delta M_{1}, \Delta M_{2}$, and $\Delta M_{3}$ are given by the row totals, and with this data we are able to compute the observed distribution of the parameter $\pi_{i j}=X_{i j} / n$, for each sub-set having a preceding strong earthquake 
Table 3. Distribution of the parameter $\pi_{i j}$, i.e., the proportion of preceding earthquakes with magnitude class $\Delta \bar{M}_{i}$ having consecutive inter-arrival time $\Delta T_{j}$. The values are calculated using Eq. (5) and the observed frequencies $X_{i j}$ from Table 2.

\begin{tabular}{ccccccccc}
\hline \multirow{2}{*}{ from $A M_{i}{ }^{*}$} & \multicolumn{10}{c}{ to $A \bar{T}_{j}^{*}$} \\
\cline { 2 - 9 } & 90 & 270 & 450 & 630 & 810 & 990 & 1,170 & 1,350 \\
\hline 6.8 & 0.137 & 0.137 & 0.059 & 0.039 & 0.020 & 0.059 & 0.020 & 0.020 \\
7.3 & 0.137 & 0.078 & 0.020 & 0.000 & 0.039 & 0.020 & 0.000 & 0.000 \\
7.8 & 0.098 & 0.020 & 0.020 & 0.000 & 0.000 & 0.000 & 0.000 & 0.000 \\
\hline
\end{tabular}

\begin{tabular}{cccccccc}
\hline \multirow{2}{*}{ from $\Delta \bar{M}_{i}^{*}$} & \multicolumn{10}{c}{ to $\Delta T_{j}{ }^{*}$} \\
\cline { 2 - 8 } & 1,530 & 1,710 & 1,890 & 2,070 & 2,250 & 2,430 & 2,610 \\
\hline 6.8 & 0.039 & 0.000 & 0.000 & 0.000 & 0.000 & 0.000 & 0.000 \\
7.3 & 0.000 & 0.000 & 0.000 & 0.000 & 0.000 & 0.000 & 0.000 \\
7.8 & 0.000 & 0.000 & 0.000 & 0.000 & 0.000 & 0.000 & 0.000 \\
\hline
\end{tabular}
scale).

magnitude class $\bar{M}_{i}, i=1,2,3$. The computed values of the parameter $\pi_{i j}$, for each row are shown in Table 3, as determined by using Eq. (5) and the numbers from Table 2.

\section{Results of the Bayesian Prediction for Mexico City}

To obtain the likelihood function we use Eq. (6), and the values of $X_{i j}, \pi_{i j}$, and $n$, as given in Tables 2 and 3 . However, to save computation time, the desired values of the likelihood function can easily be generated from tables of the Binomial probability distribution. The estimated values of the Binomial likelihood function $P\left(X_{i j} / \pi_{i j}\right)$ are shown in Table 4 , determined by using the numbers from Tables 2 and 3 substituted in Eq. (6).

Finally, we then generated the posterior or revised probabilities $P\left(\pi_{r j} / X_{r j}\right)$. To do this we substituted the values for the Binomial likelihood function given in Table 4, into Eq. (6). The estimated values of the posterior Bayesian probabilities are shown in Table 5.

From what has been described in the foregoing paragraphs it can be concluded that precise knowledge of the magnitude of the last strong earthquake felt in Mexico City could make possible a preliminary Bayesian probabilistic prediction of the length of the inter-arrival time of the next approaching strong earthquake in Mexico City. The criterion used in estimating or predicting the expected inter-arrival time is chosen from the maximum values of the estimated posterior Bayesian probabilities.

From Table 5, the more important estimation or prediction of the expected inter-arrival times derived on the basis of the $M$ maximum posterior Bayesian probabilities, may be summarized using an interpretation rule of the form $\left(\Delta \bar{M}_{i}\right.$, 
Table 4. Estimated individual values of the Binomial likelihood function $P\left(X_{i j} / \pi_{i j}\right)$. This table is determined using Eq. (6) and the $\pi_{i j}$ values given in Table 3 . However, the values are estimated from tables of the Binomial probability distribution.

\begin{tabular}{|c|c|c|c|c|c|c|c|c|}
\hline \multirow{2}{*}{ from $\Delta \bar{M}_{i}^{*}$} & \multicolumn{8}{|c|}{ to $\Delta T_{j}^{*}$} \\
\hline & 0.25 & 0.74 & 1.23 & 1.73 & 2.22 & 2.71 & 3.21 & 3.70 \\
\hline 6.8 & 0.1606 & 0.1606 & 0.2311 & 0.2762 & 0.3716 & 0.2311 & 0.3716 & 0.3716 \\
\hline 7.3 & 0.1606 & 0.2037 & 0.3716 & 0.0000 & 0.2762 & 0.3716 & 0.0000 & 0.0000 \\
\hline 7.8 & 0.1849 & 0.3716 & 0.3716 & 0.0000 & 0.0000 & 0.0000 & 0.0000 & 0.0000 \\
\hline \multirow{2}{*}{ from $\Delta M_{i}{ }^{*}$} & \multicolumn{8}{|c|}{ to $\Delta T_{1}{ }^{*}$} \\
\hline & 4.19 & 4.69 & 5.18 & 5.67 & 6.17 & 6.66 & 7.15 & \\
\hline 6.8 & 0.2762 & 0.0000 & 0.0000 & 0.0000 & 0.0000 & 0.0000 & 0.0000 & \\
\hline 7.3 & 0.0000 & 0.0000 & 0.0000 & 0.0000 & 0.0000 & 0.0000 & 0.0000 & \\
\hline 7.8 & 0.0000 & 0.0000 & 0.0000 & 0.0000 & 0.0000 & 0.0000 & 0.2762 & \\
\hline
\end{tabular}
scale).

Table 5. Estimated individual Bayesian probabilities $P\left(\Delta T_{j} / \Delta M_{i}\right)$, determined using the simplified form of Bayes' theorem, Eq. (7), and the estimated individual values of the Binomial likelihood given in Table 4.

\begin{tabular}{ccccccccc}
\hline \multirow{2}{*}{ from $\Delta M_{i}^{*}$} & \multicolumn{10}{c}{ to $\Delta \bar{T}_{j}^{*}$} \\
\cline { 2 - 9 } & 0.25 & 0.74 & 1.23 & 1.73 & 2.22 & 2.71 & 3.21 & 3.70 \\
\hline 6.8 & 0.032 & 0.032 & 0.046 & 0.055 & 0.074 & 0.046 & 0.074 & 0.074 \\
7.3 & 0.032 & 0.040 & 0.074 & 0.000 & 0.055 & 0.074 & 0.000 & 0.000 \\
7.8 & 0.037 & 0.074 & 0.074 & 0.000 & 0.000 & 0.000 & 0.000 & 0.000 \\
\hline
\end{tabular}

\begin{tabular}{cccccccc}
\hline \multirow{2}{*}{ from $A M_{i}^{*}$} & \multicolumn{10}{c}{ to $\Delta \bar{T}_{j}^{*}{ }^{*}$} \\
\cline { 2 - 8 } & 4.19 & 4.69 & 5.18 & 5.67 & 6.17 & 6.66 & 7.15 \\
\hline 6.8 & 0.055 & 0.000 & 0.000 & 0.000 & 0.000 & 0.000 & 0.000 \\
7.3 & 0.000 & 0.000 & 0.000 & 0.000 & 0.000 & 0.000 & 0.000 \\
7.8 & 0.000 & 0.000 & 0.000 & 0.000 & 0.000 & 0.000 & 0.055 \\
\hline
\end{tabular}

(Richter scale).

$\left.\Delta \bar{T}_{j}\right)$, where $\Delta \bar{M}_{i}$ refers to the midpoint strong earthquake magnitude and $\Delta \bar{T}_{j}$ refers the following midpoint inter-arrival time. Thus, the more important estimation or prediction of occurrence of the next expected inter-arrival times $\Delta T_{j}$ may be drawn from Table 5 are:

(1) For the preceding midpoint earthquake magnitude class $\bar{M}_{1}=6.8$, probabilities of occurrence are increasing fairly uniformly and variations of the amplitudes of inter-arrival times varying from 1.23 to 4.19 .

(2) For the preceding midpoint earthquake magnitude class $\bar{M}_{2}=7.3$, pro- 
babilities of occurrence are increasing fairly uniformly and variations of the amplitudes of inter-arrival times are approximately from 1.23 years to 2.17 years.

(3) For the preceding midpoint earthquake magnitude class $\bar{M}_{3}=7.8$, no specific pattern can be recognized for the maximum probabilities of occurrence of inter-arrival times. However, a single exception shows the prediction of a considerable greater inter-arrival time with maximum amplitude of 7.15 years.

\section{Estimation of the Prediction Error}

In order to evaluate the "error" in this particular prediction we follow BENJAMIN and CORNELL (1970). Forced to give a single number as "the predicted value of inter-arrival time $T$," let us assume the choice is $\mu_{T}$, i.e., the mean of the sample $\left\{T_{j}\right\}$. The uncertainty involved is this particular prediction is measured by the variance $\sigma_{T}^{2}$ of $T$ or

$$
\sigma_{T}^{2}=E\left[\left(T-\mu_{T}\right)^{2}\right],
$$

which can be interpreted as the expected value of the square "error" of prediction $\varepsilon=T-\mu_{T}$.

Now, for any other predictor, say $\tau$, it has a square error:

$$
\begin{aligned}
E\left[(T-\tau)^{2}\right] & =E\left[\left[\left(T-\mu_{T}\right)+\left(\mu_{T}-\tau\right)\right]^{2}\right] \\
& =\operatorname{Var}[T]+\left(\mu_{T}-\tau\right)^{2} .
\end{aligned}
$$

Using the data given in our catalog (Table 1) we computed $\mu_{T}=1.365$ years and $\operatorname{Var}[T]=2.812$ (years). Then, using Eq. (9) we estimated the square error $\left(\varepsilon^{2}\right)$ for each one of the predicted inter-arrival times, as follows:

(1) For large earthquakes of midpoint magnitude class $\bar{M}_{2}=7.3$ we obtained

$$
\varepsilon_{1.23}= \pm 1.68 \text { (years) }
$$

and

$$
\varepsilon_{2.17}{ }^{\prime}= \pm 1.86 \text { (years) }
$$

Thus, for the predicted inter-arrival times, we have

$$
T_{7.3}=1.23 \text { (years) } \pm 1.68 \text { (years) }
$$

and

$$
T_{7.3}{ }^{\prime}=2.17 \pm 1.86 \text { (years) . }
$$

Similarly, for the predicted inter-arrival time of the destructive earthquake of midpoint magnitude class $\bar{M}_{3}=7.8$ we have

$$
T_{7.8}=7.15 \text { (years) } \pm 6.02 \text { (years) } .
$$

Now, taking as reference the occurrence time of the last earthquake of our catalog, say the year 1979.203, we may then estimate or predict the occurrence time of the expected events (already occurred). In order to do this, we add the esti- 
mated or predicted inter-arrival times $T_{7.3}, T_{7.8}{ }^{\prime}$ and $T_{7.8}$, to the last earthquake occurrence in the year 1979.203. Thus, we predicted the following earthquakes (already occurred):

$$
\begin{aligned}
t_{7.3} & =1980.43 \text { (years) } \pm 1.68 \text { (years) } \\
t_{7.3} & =1981.37 \text { (years) } \pm 1.86(\text { years }) \\
t_{7.8} & =1986.35 \text { (years) } \pm 6.02 \text { (years) } .
\end{aligned}
$$

I wish to thank the reviewers of The Journal of Physics of the Earth for their critical review of the manuscript and for many helpful suggestions. Finally, we suggest the construction and investigation of Bayesian Models such as the one we have presented here; having various hypothesis about the prior probability $P\left(T_{j}\right)$ and about the likelihood function $P\left(M / T_{j}\right)$, it is a fruitful undertaking, because it allows one to isolate and combine the effects of two variables, earthquake magnitude $(M)$ and inter-arrival time $(T)$ using the Bayes' theorem.

\section{REFERENCES}

ABE, K., Magnitudes of large shallow earthquakes from 1904 to 1980, Phys. Earth Planet. Inter., 27, 72-92, 1981.

AKI, V., Statistics of earthquake sequence in time, U.S. Japan Conference on Earthquake Prediction, 1965.

Allen, C. R., P. St. Amand, C. F. RuchteR, and J. M. Nordquist, Relationship between seismicity and geology structure in the southern California region, Bull. Seismol. Soc. Am., 55, 753-797, 1965.

BARBER, T. D. H., Topics in Modern Mathematics 2, Pitman Publishing, London, 1973.

BufE, C. G., P. W. HARSH, and R. O. BuFORD, Steady-state seismic slip-a precise recurrence model, Geophys. Res. Lett., 4, 91-94, 1977.

CARR, M. J. and R. E. STOIBER, Geology setting of some destructive earthquakes in Central America, Geol. Soc. Am. Bull., 88, 151-156, 1977.

CONRAD, V., Zeitliche Felge der erdbeben and bebenauslesende Ursachen, Hanbuch der Geophysik, 4, 1007-1185, 1932.

DeAN, B. W. and C. L. Drake, Focal mechanism solutions and tectonics of the Middle America arc, J. Geol., 86, 111-128, 1978.

Ferraes, S. G., Earthquake magnitude probabilities and statistical independence for Mexico City earthquakes, Bull. Seismol. Soc. Am., 63(6), 1913-1919, 1973.

FERRAES, S. G., Statistical and probabilistic dependence between magnitude and time-intervals for Mexico City earthquakes, Tellus, 27(5), 529-537, 1975.

Ferraes, S. G., The Bayesian probabilistic prediction of strong earthquakes in the Hellenic arc, Tectonophysics, 111(3-4), 339-354, 1985.

Furumoto, A. S., Seismicity of Hawaii. Part I. Frequency energy distribution of earthquakes, Bull. Seismol. Soc. Am., 56, 1-12, 1966.

GARDNER, J. and L. KNOPOFF, Is the sequence of earthquakes in southern California, with aftershocks removed, Poissonian?, Bull. Seismol. Soc. Am., 64, 1363-1377, 1974.

GutenBerg, B. and C. F. Richter, Seismicity of the Earth and Associated Phenomena, Princeton University Press, Princeton, New Jersey, 1954.

HANUS, V. and J. VANEK, Subduction of the Cocos plate and deep active fracture zones of Mexico, Geof. Int., 17, 14-53, 1977-1978.

JEFFREYS, H., Aftershocks and periodicity in earthquakes, Gerlands Beitr. Geophys., 53, 111-139, 1938. 
KNopoff, L., The statistics of earthquakes in southern California, Bull. Seismol. Soc. Am., 54, 1871-1873, 1964.

LARSON, J. H., Introduction to Probability Theory and Statistical Inference, John Wiley \& Sons Inc., New York, 1974.

Lommitz, C., Statistical prediction of earthquakes, Rev. Geophys., 4, 377-393, 1966.

MolNAR, P. and L. SYKes, Tectonics of the Caribbean and Middle American regions from focal mechanisms and seismicity, Geol. Soc. Am. Bull., 80, 1639-1684, 1969.

Ogawara, M., Probability of the Coming Felt Earthquake in Tokyo, U.S. Japan Conference on Earthquake Prediction, 1965.

OMORI, F., On the aftershocks of earthquakes, J. Coll. Sci. Imp. Univ. Tokyo, 7, 111-120, 1894.

Parsons, R., Statistics for Decisions Makers, Harper and Row Publishers, New York, 1974.

Powell, J. A. and S. J. DudA, A Statistical Study of Earthquakes Occurrence, Pageoph, Vol. 113, 447-466, Verlag, 1975.

ProchásKová, D., Migration of Earthquake Foci in Europe, Pageoph. V, Vol. 111 (1973-IX), 2005-2011, Verlag, 1973.

RundLe, J. B. and D. D. JACKson, Numerical simulation of earthquakes sequences, Bull. Seismol. Soc. Am., 67(5), 1363-1377, 1977.

ShIMAZAKI, K. and T. NAKATA, Time-predictable model for large earthquakes, Geophys. Res. Lett., 7(4), 279-282, 1980.

Singh, S. K., M. Rodrigaez, and L. Esteva, Statistics of small earthquakes and frequency of occurrence of large earthquakes along the Mexican subsuction zone, Bull. Seismol. Soc. Am., 73(6), 1779-1796, 1983.

TAYLOR, L. D., Probability and Mathematical Statistics, Harper and Row Publishers, New York, 1974. 